\title{
Household Energy Consumption in Nigeria: A Review on the Applicability of the Energy Ladder Model
}

\author{
${ }^{*}$ ADAMU, MB; ${ }^{2} \mathrm{ADAMU}, \mathrm{H} ;{ }^{3} \mathrm{ADE}, \mathrm{SM} ;{ }^{2} \mathrm{AKEH}, \mathrm{GI}$ \\ ${ }^{*}$ Department of Architecture, ${ }^{2}$ Department of Environmental Management Technology, \\ ${ }^{3}$ Department of Surveying and Geo-informatics, Faculty of Environmental Technology, Abubakar Tafawa Balewa University Bauchi, \\ Nigeria \\ *Corresponding Author Email: mababayo@atbu.edu.ng; Tel: +2348035004237
}

\begin{abstract}
Household energy consumption dynamics in developing countries is often conceptualized through the Energy ladder model and assumes that with increasing income, householders will have a preference to cleaner energy. This paper reviewed various energy sources for household consumption and examines the implications of their dependence on traditional energy sources as well as the energy ladder model as a concept widely used by scholars in describing the role of income in determining energy use and choices. It further explains the consumption behaviour of households in relation to the major assumptions of the model. The paper posits that the dependence on energy sources at the lowest rung of the energy ladder by most households in Nigeria is accentuated by rising poverty level consistent with the energy ladder hypothesis but disagrees with the notion of complete fuel substitution given that most households tend to have a mix of energy sources for their activities It recommends that government and other stakeholders should formulate policies that will foster the use of modern energy sources with a view to mitigating the environmental and health externalities of traditional energy use as well as improving the quality of human lives.
\end{abstract}

\section{DOI: https://dx.doi.org/10.4314/jasem.v24i2.7}

Copyright: Copyright $(02020$ Adamu et al. This is an open access article distributed under the Creative Commons Attribution License (CCL), which permits unrestricted use, distribution, and reproduction in any medium, provided the original work is properly cited.

Dates: Received: 16 November 2019; Revised: 11 January 2020; Accepted: 22 February 2020

Keywords: Households, energy consumption, energy ladder model, income

The importance of energy in human lives cannot be overemphasized; it is central to all aspects of economic growth, progress and development as well as poverty eradication and security (Akinola, et al., 2017). Energy plays a critical role in enhancing production, competitiveness and incomes through its support to productive activities and the facilitation of investments in industry, commerce and agriculture (World Bank, 2007). Access to modern forms of energy is therefore essential to overcome poverty, promote economic growth and employment opportunities, support the provision of social services and in general promote sustainable human development (Karekezi, et al., 2012). Generally, household energy services are required for a variety of purposes. It is required for lighting, heating, cooking and for use in electrical appliances. This usage is commonly referred to as household energy consumption and is defined as the energy consumed in homes to meet the needs of households (Kadiri and Alabi, 2014). Based on usage, household energy includes fuel wood, dung, agricultural residues, charcoal, kerosene, Liquefied Petroleum Gas (LPG) and electricity. An energy source in its raw state before conversion into mechanical work is said to be primary energy while secondary energy refers to the transformed state of all primary energy forms. Primary or secondary forms of energy that must be subjected to combustion or fission to release their stored energy are referred to as fuels (Adetunji, et al., 2007). Emagbetere, et al (2016) identified two classes of energy utilized in household as solid fuels and nonsolid fuels. The solid fuels include fossil fuels (coal and peat) and biomass (wood, dung and agricultural residues), while the non-solid fuels consist of kerosene, liquefied natural gas and electricity. The International Energy Agency (IEA, 2002) reports that about 30 to $40 \%$ of all primary energy is used in residential buildings thus making the built environment responsible for a large share of the world's total energy consumption. Consequently, the household sector is therefore seen as one of the most important energy consuming sectors in the world (Wang, et al., 2011). In Nigeria, the household sector accounts for the largest share of about $65 \%$ of energy usage (Oyedepo, 2012). In 2003, the Energy Commission of Nigeria estimated that over $60 \%$ of Nigerian population depended on fuel wood for cooking and other domestic uses and rose to $72 \%$ in 2004. According to the International Energy Agency (IEA, 2006), about 2.5 billion people rely on these unclean fuels for their household requirements in 
developing countries including Nigeria. The World Bank (2007) report indicates that $74 \%$ of households in Asia use traditional energy sources mostly in the form of biomass. The situation is not much different in Nigeria where traditional energy sources account for over $70 \%$ of household energy supply. While rural households rely more on biomass fuels than those in urban areas, a substantial number of urban households in Nigeria still rely on fuel wood, charcoal and wood waste to meet their energy needs for cooking (Madukwe, 2014). According to the IEA (2006), this proportion is likely to increase given the projection that $61 \%$ of the world's population will be living in urban areas by 2025 . Although there are various sources of energy available for household consumption, some of those sources particularly those at the lowest rung of the energy ladder such as fuel wood and charcoal have been known to cause environmental degradation and health problems (Aderemi, et al., 2009). For instance, the consumption of traditional biomass is responsible for indoor air pollution, forest depletion and Green House Gas (GHG) emissions (Toole, 2015; Muller and Yan, 2016). The World Health Organization (WHO, 2010) estimates that over 1.5 million people die prematurely every year as a result of illnesses attributable to indoor air pollution from the consumption of solid fuels. Many scholars have used the energy ladder to conceptualize household energy dynamics in developing countries (Arthur, et al., 2010; Kowasari and Zerriffi, 2011). These studies have produced various outcomes with regards to the variables that drive household energy consumption (Alem, et al., 2015). Nevertheless, the role of income in determining energy use and fuel choices is common with most empirical studies. Understanding household energy consumption behaviour is therefore of significant importance in the search for policies and interventions to support a transition to cleaner and efficient forms of energy (van der Kroon, et al., 2013). It is against the above backdrop that this paper is written to analyze how household energy consumption behaviour in Nigeria is influenced by the energy ladder model. It is expected that the review will provide information on the complex factors that drive household energy transition in the context of the energy ladder model so as to facilitate policy design and interventions that will promote the use of cleaner and efficient fuels thus improving the quality of lives of households in developing countries particularly Nigeria.

\section{MATERIALS AND METHOD}

Data for this study was obtained from existing literature on household energy demand in developing countries including Nigeria. It involved a synthesis and critical analysis of existing literature on household energy consumption having regards to the Energy ladder model.

\section{RESULTS AND DISCUSSION}

Household energy sources: Some of the most commonly used household energy sources in developing countries including Nigeria have been discussed below:

Biomass: Biomass occupies the lowest rung of the energy ladder. It refers to any naturally occurring combustible material. Biomass fuels play a key role in household cooking fuels. According to the World Bank (2007), many urban households use biomass fuels for cooking in developing countries such as Nigeria. Biomass fuel is largely free and relatively available to most communities. Fuel wood is a major component within this classification, but grasses, crop residues, or dung also fall under biomass. Dung is perhaps the least desirable form of biomass and its use indicates extreme fuel poverty (Goldemberg, 2000).

A World Energy Assessment conducted by the United Nations Development Programme (UNDP) and the World Energy Council estimated the efficiency of fuel wood, for example, at $15 \%$ as compared to kerosene at $50 \%$ and gas at $65 \%$ efficiency (Goldemberg 2000). Related to its inefficiency, biomass does not burn cleanly. Of all types of energy sources on the ladder, burning biomass releases the greatest emissions of carbon dioxide, sulphur dioxide, and particulates, leading to both indoor and outdoor air pollution (Goldemberg, 2000; van Rujiven 2008; Heltberg, 2005). Indoor air pollution poses substantial health hazards to users, including acute respiratory infections, chronic obstructive pulmonary diseases, eye and vision issues, and lung cancer (Heltberg, 2005). Babies born to women exposed to indoor air pollution also face the risk of stillbirth and low birthweight (Goldemberg, 2000).

Charcoal: Charcoal is a solid fuel derived from wood through a process called pyrolysis, which involves heating the wood to burn off most of the material and therefore leave nearly pure carbon (Toole, 2015). Consequently, charcoal shares a number of advantages and disadvantages with biomass. A historical and cultural fuel, charcoal preserves the taste of many traditional cooking fuels in contrast to modern energy sources (Nansaior et al., 2011). Like biomass, charcoal emits organic and nonorganic compounds harmful both to human health and the environment. The degree of the deleterious fumes emitted is often less than wood due to the stoves sometimes used in conjunction with charcoal (Toole, 2015). 
Kerosene use: Kerosene lies on the rung just above charcoal. Kerosene is derived from petroleum and is produced during the distillation of crude oil. Lam et al., (2012) defined kerosene as the proportion of crude oil that boils when heated between 145 and $300^{\circ} \mathrm{C}$. It is a fairly volatile liquid widely used by many household as the main source of energy for cooking, lighting lamps, burning bush, fuel for automobiles (Sa'ad and Bugaje, 2016). It is also used as insects repellent because of its odour. Compared to its immediate predecessor and biomass, kerosene burns more cleanly and more efficiently, an advantage in terms of both user health and the environment.

Furthermore, kerosene requires substantial expenditures at the first instance of purchase because combusting the fuel requires additional equipment. These fixed costs may deter use, particularly if the household faces liquidity or credit constraints (van der Kroon et al., 2013). Lastly, some households consider the taste of food cooked using kerosene to be inferior to that of wood-cooked (Maconachie et al., 2009).

Liquid Petroleum Gas: Liquefied Petroleum Gas (LPG) lies above kerosene on the energy ladder. Like kerosene, LPG is derived from petroleum contains propane, butane, or a combination of the two. LPG has increased efficiency and cleanliness of combustion and allows for quicker heating of food or water with fewer emissions (Toole, 2015). In particular, LPG releases much less sulphur dioxide than kerosene or biomass (Goldemberg, 2000). LPG is conventionally available through the petroleum and gas industry. Its distribution, according to Egbuna (1987) is mainly concentrated in urban areas.

Electricity: Electricity claims the highest position on the energy ladder. Electricity is a secondary fuel dependent on the transformation of other sources of energy and required a high-tech environment. Electricity is used for a number of purposes that include industrial, commercial and household purposes (Babatunde and Shuaibu, 2010). Access to electricity is particularly crucial to human development as electricity, in practice, is indispensable for certain basic household activities such as lighting, refrigeration and running of household appliances and cannot easily be replaced by other forms of energy (IEA, 2002).

Implications of household's dependence on traditional energy sources in Nigeria

Although access to affordable, reliable, sustainable and modern energy is one of the Sustainable Development Goals (SDGs), statistics indicate that 2.5 billion people in developing countries still rely heavily on traditional fuels for their household needs (IEA, 2006). In Nigeria, traditional energy sources account for over $70 \%$ of household energy supply (Maduekwe, 2014). Households in most developing countries are highly dependent on traditional fuels for cooking, heating and lighting with negative health and environmental externalities (Toole, 2015).

The rate at which trees are felled exceeds the rate at which they are replaced and this is due largely to high demand for fuel wood. Available estimate show that Nigeria consumes over 50 million metric tonnes of fuel wood annually, a rate which exceeds the regenerative abilities of forests to meet future needs creating concerns that the country's 15 million hectares of forest and woodland resources could be depleted within the next fifty years (Energy Commission of Nigeria, 2003). According to Sa'ad and Bugaje (2016), the main drivers of traditional fuels consumption in Nigeria include poverty, availability, cost and cultural factors. They reported that the smooth transition to clean and modern energy sources by households is made difficult due to the expensive nature and uneven distribution of modern energy sources such as kerosene, LPG and electricity in Nigeria.

The National Bureau of Statistics in 2007 found that North-east Nigeria with a poverty rate of $72.2 \%$ consumed $95.9 \%$ of traditional fuels. North-central and North-west with poverty rates of $71.2 \%$ and $67.2 \%$ consumed $95.3 \%$ and $86.4 \%$ of traditional fuels respectively. In contrast, south-west Nigeria with a poverty rate of $43 \%$ consumed $54.9 \%$ of traditional fuels while South-east and South-south with poverty rates of $26.7 \%$ and $35.1 \%$ consumed $78 \%$ and $72.1 \%$ of traditional fuels respectively. This staggering statistics show the very strong correlation between poverty and forest degradation associated with fuel wood exploitation in Nigeria.

The overdependence on fuel wood exacerbates the process of deforestation and forest degradation (Toole, 2015). The consumption of fuel wood as a source of household energy leads to carbon dioxide $\left(\mathrm{CO}_{2}\right)$ emissions, a main greenhouse gas, through combustion as well as the depletion of forests, which is an important $\mathrm{CO}_{2}$ sink creating increasing concerns for climate change. In Nigeria, the rate of deforestation due to fuel wood exploitation is estimated to be about 400,000 hectares per year. The consumption of traditional fuels by households is a major cause of health problems in developing countries including Nigeria due to indoor air pollution (Ezzati and Kammen, 2001). Fuel wood and other solid fuels consumption by households expose women and 
children to high levels of indoor air pollution, which according to the World Health Organization (WHO), is responsible for over 1.5 million premature deaths per year.

In States like Yobe and Borno, where desert is fast encroaching, the average distance for fuel wood collection is over $5 \mathrm{~km}$ per day (Sa'ad and Bugaje, 2016). Collection time has a significant opportunity cost, limiting the opportunity for women and children to improve their education and engage in other productive economic activities. Many children, especially girls, are withdrawn from school to attend to domestic chores related to biomass fuel use thus reducing their literacy and restricting their economic opportunities. Physical exhaustion due to distance covered in searching for fuel wood has also been reported (Adetunji, et al., 2007).

The adverse effects associated with traditional fuels require urgent intervention to stem the tide of fuel wood consumption and drive policies that will make households accessible to modern and efficient sources of energy. There is the need to encourage households to shift from the use of less efficient energy sources to the adoption of more efficient ones. Moving towards the use of cleaner fuels is an important option to improve the standard of living for countries that rely heavily on traditional fuels (Lee, 2013).

Adetunji, et al (2007), for instance have advocated for the improvement of household purchasing power through the implementation of schemes that can increase households' income level in a manner that would encourage them to use easily accessible and durable energy. Access to clean, efficient, affordable and reliable energy services will therefore help in reducing poverty, improving health of citizens, promoting gender equality and enhancing sustainable management of natural resources. Buba et al (2017) recommended that a vigorous policy should be put in place towards reducing the incidence of poverty through provision of social security insurance scheme and policy that will improve the living condition of vulnerable groups such as women and children in Nigeria.

The energy ladder model as a concept in household energy consumption: Household energy consumption is often analyzed and understood through the energy ladder model (van der Kroon et al., 2013). The fuels on the energy ladder are ordered according to households' preferences based on physical characteristics including cleanliness, ease of use, cooking speed and efficiency (Hiemstra-van der Horst and Hovorka, 2008). The central idea of the energy ladder hypothesis is that households will shift to the use of modern energy sources like kerosene, LPG and electricity as their income improves. The theoretical assumption underlying the energy ladder hypothesis is that low living standards induce greater dependence on firewood and other biomass fuels owing to a combination of income and substitution effects (Baland, et al., 2007). Empirical literature on household energy demand and choice has shown that households in transition (that is, those between low income and high income) consume transition fuels such as charcoal and kerosene. While low income households use biomass fuels, higher income households consume energy that is cleaner and more expensive such as liquefied petroleum gas and electricity (Barnes and Floor, 1999; Heltberg, 2005). Based on this, most empirical studies tend to agree that income is a key determinant of total energy demand. However, differences in the measures of income used in these studies make their comparison difficult. The concept of the energy ladder model is one that shows how improvement in energy use correlates with an increase in the household income It assumes that as income increases, households would substitute lower quality fuels for higher quality types that are cleaner, more efficient and modern. According to the World Health Organization, over three billion people worldwide use energy sources such as biomass fuels, crop waste, dung, wood, leaves, and coal at the lower rung of the energy ladder to meet their energy needs with a large number of these people in Africa and Asia. According to Hosier and Dowd (1987), households at lower levels of income tend to be at the bottom of the energy ladder using fuel that is cheap and locally available but not very clean nor efficient. The basic notion of the Energy Ladder Model is that as income rises, households tend to climb upwards along an invisible energy ladder (Leach, 1992), and while climbing upwards, they move away from polluting and low quality traditional fuels (e.g. firewood, charcoal) placed on the lowest rung of the ladder (Kowsari and Zerriffi, 2011; van der Kroon et al., 2013). Low income households generally use traditional stoves and cooking fuels such as animal dung, charcoal and wood, while those households with higher income used modern cooking technology and fuels. As income increases, households transit from traditional fuels and cooking stoves to modern fuels and cooking technology. Thus, the theoretical assumption underlying the energy ladder hypothesis is that low living standards induce greater dependence on firewood and other biomass fuels owing to a combination of income and substitution effects (Baland, et al., 2007). Thus, there is a positive relationship between income and modern fuel uptake and fuel preferences are ordered by physical 
characteristics and fuel costs with the assumption of complete substitution of one fuel for another as income increases (Kayode, 2016).

There are several studies in literature that seem to support the Energy ladder hypothesis with regards to household energy consumption particularly in developing countries. For instance, Rajmohan and Weerahewa (2007) investigated household energy consumption patterns of urban, rural and estate sectors in Sri Lanka. The results show that the energy ladder hypothesis holds for Sri Lanka and the country as a whole is moving towards modern fuels such as LPG and electricity. Numerous studies point to income as the major driver behind the uptake of modern fuels (Brew-Hammond, 2010; Peng et al., 2010; Kowsari and Zerriffi, 2011). Hosier and Dowd (1987) found that Zimbabwean urban households tend to move away from wood, towards kerosene and electricity, as their income rises. Ouedraogo (2006) observed in Burkina Faso that a higher income induced urban households to choose natural gas over kerosene. Baiyegunhi and Hassan (2014) show in rural Nigeria that the transition from fuel wood to kerosene, natural gas and electricity occurs along to rising income. Nansaior, et al (2011) found that there was a decline in the use of biomass in an urban community within the study area of northern Thailand. Similarly, Abd'razack, et al., 2012) in Nigeria found a significant relationship between choice of energy and income in support of the energy ladder model.

Analysis of the energy ladder model in household energy consumption: Although the energy ladder model is reputed for its ability to explain the income dependency of fuel choices, it has been criticized as being insufficient to represent actual energy consumption dynamics due to several other social and economic factors (Foster, 2000; Masera, 2000). It has been argued that households in developing countries do not switch to modern energy sources but instead tend to consume a combination of fuels which may include combining solid fuels with non-solid fuels as sources of energy. Hence, instead of moving up the ladder step by step as income rises, households choose different fuels as from a menu (Mekonnen and Kohlin, 2009). In other words, a move up to a new fuel does not necessarily means a simultaneous move away from previously used fuels as implied by the energy ladder model. Empirical evidence has shown that fuel stacking is common in most urban and rural households in developing countries. Fuel stacking corresponds to multiple fuel use patterns where households choose a combination of fuels from both lower and upper levels of the ladder. Indeed, modern fuels may serve only as partial, rather than perfect substitutes for traditional fuels (van der Kroon et al., 2013). Taylor, et al (2011) found that despite the nearly universal ownership of LPG stoves amongst migrant households in Guatemala, 77\% maintained fuel wood as their primary form of fuel consistent with multiple fuel use. Similarly, a study by Ngui, et al (2011) reveals multiple fuel use by households in Kenya. Evidence from urban Ethiopia, using panel data collected in the years 2000 and 2004 indicates that multiple fuel use better describes fuel choice of households (Mekonnen and Köhlin, 2008). Thus, most studies seem to suggest that economic factors are not the only determinants of household's fuel choice. Several socio-demographic factors such as education and gender of the household heads are also important factors (Farsi, et al., 2007). The reasons for multiple fuel use are varied and not dependent on economic factors alone but cultural or habitual factors, education, fuel availability, household composition, tradition and urbanization (Toole, 2015). Education is also another important household characteristic that has been included in studies on energy consumption. Studies by Narasimha and Reddy (2007) in India, Mekonnen and Köhlin (2008) in urban Ethiopia, Farsi et al (2007), Njong and Johannes (2011) and Heltberg (2005) are some of the examples which underline the importance of education or awareness in reducing the demand for traditional fuels such as firewood. According to Farsi et al (2007) better education helps households to be aware of the negative effects of using biomass fuels such as firewood, and increases the awareness with regard to the advantages of modern fuel use, in terms of efficiency and convenience. Chambwera and Folmer (2007) noted that education can be considered as a long-term policy to handle and manage the demand for firewood. Gupta and Kohlin (2006) argued that availability and ease of use are very important for the choice of fuel. Fuel choice is also correlated with other variables such as ethnicity and region of residence. For example, Narasimha and Reddy (2007) examined fuel choice decision of households separately for rural and urban households of India and found that the factors that affect fuel choice are entirely different in the two areas. Studies have also shown that households' characteristics affect the choice of fuels in developing countries. For instance, almost all studies find that household size is a key determinant of fuel choice. As household size increases, the household switches to other fuel types such as charcoal, fuel wood and LPG to meet increased demand for energy (Ngui et al., 2011). A large household size with many females translates into low opportunity costs to collect firewood and therefore often leads to fuel stacking. This view is supported by van der Kroon, et al (2013) as well as Narasimha and Reddy (2007). Heltberg (2004) analyzed the 
determinants of fuel switching using comparable household survey data from Brazil, Ghana, Guatemala, India, Nepal, Nicaragua, South Africa, and Vietnam. His results show that household size affects fuel choice but does not trigger fuel switching. He argued that larger households are more likely to consume multiple fuels, both biomass and nonbiomass. It is therefore obvious from the above review that though income plays a dominant influence in fuel switching, it is by no means the only factor that influences household energy consumption and fuel choice in most developing countries. In addition, contrary to the energy ladder model that fuel substitution takes place in households, the review from most developing countries shows that households tend to use multiple fuels for their daily needs. However, there is the need for more empirical findings to examine whether fuel substitution takes place in Nigerian households.

Conclusion: The paper reveals that the energy ladder theory only provides a limited view of reality in households. It shows that beyond income, there is an intricate web of closely interrelated socio-economic factors that drive household energy transition and the extent of the influence of those factors vary widely among countries. The study presents a more comprehensive and up-to-date review of the existing empirical findings on household energy transition in Nigeria. It is recommended that government and other stakeholders in energy issues should formulate policies that will foster the use of modern fuels thereby facilitating the upward movement of households to cleaner energy sources.

\section{REFERENCES}

Abd'razack, NTA; Medayese, SO; Matins, V I; Idowu, OO; Adeleye, BM; Bello, LO (2012). An appraisal of household domestic energy consumption in Minna, Nigeria. IOSR J. Environ Sci, Toxicol \& Food Technol. 2(3): 16-24.

Aderemi, AO; Ilori, MO; Aderemi, HO; Akinbami, JFK (2009). Assessment of electrical energy use efficiency in Nigeria food industry. Afr. J. Food Sci. 3(8): 206-216.

Akinola, AAO; Oginni, OT; Rominiyi, OL; Eiche, JF (2017). Comparative study of residential household energy consumption in Ekiti State, Nigeria. British J. Appl. Sci \& Technol. 21(2): 110 .

Alem, Y; Beyene, AD; Kohlin, G; Mekonnen, A (2015). Modelling household cooking fuel choice: A panel multinomial logit approach. Working papers in Economics No 632. University of Gothenburg.

Arthur, MSR; Zahran, S; Bucini, G (2010). On the adoption of electricity as a domestic Source by Mozambican households. Energy Pol.38 (11): 7235-7249.

Babatunde, MA; Shuaibu, M I (2010).The demand for residential electricity in Nigeria: A bound testing approach to the analysis of level of relationships. J. Appli. Econo. 16(3) 289-326.

Baiyegunhi, LJS; Hassan, MB (2014). Rural household fuel energy transition: Evidence from Giwa LGA Kaduna State, Nigeria. Energy for Sustain. Develop. 20: 30-35.

Baland, J; Bardhan, P; Das, S; Mookherjee, D; Sarkar, R (2010). The Environmental Impact of Poverty: Evidence from Firewood Collection in Rural Nepal. Econ. Develop. \& Cultural Change 59, 23-61.

Barnes, DF; Floor, WM (1996). Rural energy in developing countries: a challenge for economic development. Annual Review of Energy Environ. 21, 497-530.

Brew-Hammond, A (2010). Energy access in Africa: Challenges ahead. Energy Policy 38 (5): 22912301.

Chambwera, M; Folmer, H (2007). Fuel Switching in Harare: An Almost Ideal Demand System Approach. Energy Policy 35: 2538-2548.

Egbuna, DO (1987). The environmental hazards of Nigerian gas industry. The 1987 Nigeria National Petroleum Corporation's seminar, Lagos, Nigeria.

Emagbetere, E; Odia, J; Oreko, BU (2016). Assessment of household energy utilized for cooking in Ikeja, Lagos State, Nigeria. Nig. J. Technol. 35(4): 796 - 804.

Farsi, M; Filippini, M; Pachauri., S (2007). Fuel choices in urban Indian households. Environ. \& Develop. Econ. 12, 757-774.

Foster, V; Tre, J; Wodon, Q (2000). Energy Prices, Energy efficiency and Fuel Poverty. World Bank Mimeo.

Goldemberg, J (2000). World Energy Assessment: Energy and the Challenge of Sustainability. United Nations Publications. 
Gupta, G; Kohlin, G (2006). Preferences for domestic fuel: Analysis with socio-economic factors and rankings in Kolkata, India. Ecological Econ. 57, 107-121.

Heltberg, R (2005). Factors determining household fuel choice in Guatemala. Environ. \& Develop. Econ. 10, 337-361

Hiemstra-van der Horst, G; Hovorka, AJ (2008). Reassessing the energy ladder household energy use in Maun, Botswana. Energy Policy, 36 (9): 3333-3344.

Hosier, RH; Dowd J (1987). Household fuel choice in Zimbabwe: An empirical test of the energy ladder hypothesis. Res. \& Energy, 9 (4): 347-361.

International Energy Agency (2002). World Energy Outlook 2002 (2nd ed.) Paris, France: IEA publications.

International Energy Agency (2006). World Energy Outlook 2006 (3rd ed.): Energy for cooking in developing countries. Paris, France. IEA publications.

Kadiri, KO; Alabi, OA (2014). Household energy consumption pattern in Offa City, Kwara State, Nigeria. J. Sci. Research \& Report, 3(11): 14991506.

Karekezi, S; McDade, BB; Kimani, J (2012). Energy, Poverty and Development. In GEA, Global Energy Assessment-Towards a Sustainable Future. Cambridge University Press, Cambridge, UK and New York, USA and the International Institute for Applied Systems Analysis, Luxemburg, Austria.

Kayode, O (2016). Analysis of household energy consumption in Ibadan metropolis of Nigeria. Unpublished $\mathrm{PhD}$ thesis, South Bank University

Kowsari, R; Zerriffi, H (2011). Three dimensional energy profile: A conceptual framework for assessing household energy use. Energy Policy, 39 (12): 7505-7517.

Lam, NL; Kirk RS; Alison G; Michael NB (2012). Kerosene: A review of household uses and their hazards in low-and middle-income countries. $J$. Toxicol. \& Environ. Health, Part B 15 (6): 396432.
Leach, G. (1992). The energy transition. Energy Policy, 20, 116-123.

Maconachie, R; Tanko, A; Zakariya, M (2009). Descending the energy ladder? Oil price shocks and domestic fuel choices in Kano, Nigeria. Land Use Policy 26 (4): 1090-1099.

Maduekwe, CE (2014). Domestic energy usage pattern of households in selected urban and rural communities of Enugu State. M.Sc. thesis, Institute for Development Studies, University of Nigeria, Enugu Campus.

Masera, OR; Saatkamp, BD; Kammen, DM (2000). From linear fuel switching to multiple cooking strategies: A Critique and alternative to the energy ladder model. World Develop. 28 (12): 20832103.

Mekonnen A; Kohlin, G (2008). Determinants of household fuel choice in major cities in Ethiopia. Working papers in economics No. 399, University of Gotenburg.

Muller, C; Yan, H (2016). Household fuel use in developing countries: Review of theory and evidence. Energy Econ.70, 429-439.

Nansaior, AP; Rambo, T; Simaraks, S (2011). Climbing the energy ladder or diversifying energy sources? The Continuing Importance of Household use of Biomass Energy in Urbanizing Communities in Northeast Thailand. Biomass \& Bioenergy, 35 (10): 4180- 4188.

Narasimha, MR; Reddy, BS (2007). Variations in Energy Use by Indian households: An Analysis of Micro Level Data. Energy 32:143-153.

Ngui, D; Mutua, J; Osiolo, H; Aligula, E (2011). Household energy demand in Kenya: An application of the linear approximate almost ideal demand system (LA-AIDS). Energy Policy 39: 7084-7094.

Njong, AM; Johannes, TA (2011). An analysis of domestic cooking energy choices in Cameroon. European J. Social Sci. 20 (2).

Ouedraogo, B (2006). Household energy preferences for cooking in urban Ouagadougou Burkina Faso. Energy Policy, 34, 3787-3795.

Oyedepo, O. (2012). Energy and sustainable development in Nigeria: The way forward. Energy Sustain Soc 2:15 
Peng, W; Zerriffi, H; Pan, J (2010). Household level fuel switching in rural Hubei. Energy for Sustain. Develop. 14 (3): 238-44.

Rajmohan, K; Weerahewa, J (2007). Household energy consumption patterns in Sri Lanka. J. Agricul. Econo. 9(1), 55-77.

Sa'ad, S; Bugaje, IM (2016). Biomass consumption in Nigeria: Trends and policy issues. J. Agricul. \& Sustain. 9(2): 127-157.

Taylor, MJ; Moran-Taylor, MJ; Castellanos, EJ; Elías, S (2011). Burning for sustainability: Biomass energy, international migration and the move to cleaner fuels and cookstoves in Guatemala. Annals of the Assoc. of American Geog. 101 (4): 918-928.

Toole, R (2015). The energy ladder: A valid model for household fuel transition in Sub Saharan Africa? MSc thesis submitted to the Department of Urban and Environmental planning and Economics. Tufts University, USA. van der Kroon, B; Brouwer, R; van Beukering, JH (2013). The energy ladder: Theoretical myth or empirical truth? Results from a meta-analysis. Renew. \& Sustain. Energy Reviews 20: 504-513.

van Ruijven, B; Urban, F; Benders, RMJ; Moll, HC; Van Der Sluijs, JP; Bert DV; Detlef, PVV (2008). Modeling energy and development: An evaluation of models and concepts. World Develop. 36 (12): 2801-2821.

Wang, Z; Zhang, B; Yin, J; Zhang, Y (2011). Determinants and policy implication of household electricity saving behaviour: Evidence from Beijing China. Energy Policy 39, 3550-3557.

WHO (2010). Household air pollution and health. USA: Fact Sheet No 292.Geneva.

World Bank (2007). Household energy use in developing countries (Series No. 5). Washington D.C., U.S.A: 